\title{
Bone histomorphometry in diabetes mellitus
}

\author{
C. A. Moreira ${ }^{1,2}$ - D. W. Dempster ${ }^{3,4}$
}

Received: 16 June 2015 / Accepted: 22 July 2015 /Published online: 5 August 2015

(C) International Osteoporosis Foundation and National Osteoporosis Foundation 2015

Diabetes mellitus (DM) is a common disease with many complications; recently, one more complication has been associated with DM, an increased risk of fragility fractures [1-3]. Both type 1 and type 2 diabetes patients display an increase in bone fragility, which appears to be somewhat independent of bone mineral density (BMD) [4]. In fact, type 2 diabetes (T2D) patients have, in general, normal BMD while type 1 patients (T1D) have low BMD, which may contribute to fracture risk, but does not fully account for it $[5,6]$. In this regard, a study analyzing bone material strength (BMS) using microindentation testing in vivo, demonstrated that postmenopausal women with T2D had lower BMS, and therefore compromised bone material properties, which were negatively correlated with glycated hemoglobin [7]. This suggests that the excess fracture risk in diabetes may be related to poor bone quality, raising questions regarding bone structure, material properties, and remodeling activity in these patients. In addition, poor glucose control and hypoglycemia besides other features related to the diabetic patient such as impaired vision

\section{A. Moreira}

carolina.aguiar.moreira@gmail.com

D. W. Dempster

ddempster9@aol.com

1 Department of Internal Medicine and Bone Unit of Endocrinology Division of Federal University of Parana (SEMPR- UFPR),

Curitiba, PR, Brazil

2 Laboratory P.R.O (Bone Histomorphometry Division), Pro Renal Foundation, Curitiba, PR, Brazil

3 Regional Bone Center, Helen Hayes Hospital, West Haverstraw, NY, USA

4 Department of Pathology, College of Physicians and Surgeons of Columbia University, New York, NY, USA and balance due to retinopathy and neuropathy increase fall and fracture risk. [8].

There are just a few studies on bone histomorphometry in diabetes with only one study in T1D [9]. Armas et al. [9] performed histomorphometric and micro-CT measurements on 18 patients with T1D with a mean duration of disease of 15 years; 5 of the subjects had a history of fragility fractures. This cohort had reasonable glucose control with half of the subjects presenting with Hbalc levels lower than $7 \%$. Bone biopsies were compared with those from age-matched controls. Overall, there were no significant differences between patients and controls in the structural parameters measured by the two techniques. However, those patients with fractures had structural and dynamic trends different from the nonfracturing subjects by both methods of analysis. Their trabeculae were more "rod-like" than "plate-like", presumably contributing to their bone fragility. In addition, fracturing patients demonstrated a trend towards lower bone remodeling parameters than those without fractures, but the only statistically significant difference was a lower mineralization lag time in T2D [10].

The first histomorphometric study of T2D was published in 1964 by Klein et al., who showed an increase of cortical area of the ribs [11]. In contrast, Leite Duarte and Silva [12] in 1996 demonstrated a significant decrease in cancellous and cortical structural parameters (e.g., bone volume, cortical thickness) in 26 diabetic patients (50-89 years of age) when compared to matched controls. These structural deficiencies were accompanied by a decrease in bone formation, as indicated by lower osteoblast surface. Furthermore, a study with 8 patients aged 37-67 years, 6 of whom had T2D and 2 had T1D showed that bone remodeling parameters (e.g., mineralizing surface, mineral apposition rate, and bone formation rate) were significant lower in T2D than controls, suggesting an osteoblast dysfunction [13]. More recently, Manavalan 
et al. [14] published an interesting study showing a decrease in tetracycline-based bone formation parameters in subjects with T2D (aged $58 \pm 6$ years) compared to age-matched controls. Biochemical markers of bone formation and resorption were also lower in the diabetic patients than the controls, confirming the histomorphometric findings. Other studies have also demonstrated a reduction in bone markers, accompanied by lower circulating PTH levels [15-17] Furthermore, a combination of reduced serum PTH and osteocalcin predicted vertebral fracture risk independent of lumbar spine BMD [15]. Sclerostin, an inhibitor of the Wnt canonical pathway, was demonstrated to be high in T2D and was associated with increased vertebral fracture risk [16-19]. Furthermore, in addition to increased serum sclerostin, reduced serum IGF-1 levels were also associated with vertebral fractures in postmenopausal women with diabetes [19].

Besides the alteration in bone microstructure and remodeling demonstrated by bone histomorphometry, the bone matrix in diabetes appears to have compromized material properties due to accumulation of advanced glycation end products (AGEs) [20, 21]. Decreased bone strength has been associated with the accumulation of AGEs, which occurs as a result of hyperglycemia and aging. In this regard, an increase in urinary pentosidine was related to an increase in vertebral fractures in T2D [20].

In summary, the only histomorphometric study in T1D to date revealed little difference from controls. There may be subtle differences in cancellous bone structure and bone formation dynamics in those with T1D who had fractures. By contrast, in T2D, bone histomorphometry and biochemical markers have clearly demonstrated reduced cortical thickness and cancellous bone volume, accompanied by reduced bone formation and turnover. The skeletal phenotype in T2D therefore appears to be characterized by low bone turnover. All these findings may indicate that anabolic agents, such as PTH peptides and sclerostin inhibitors, may be a promising therapeutic option in diabetic patients with bone fragility.

\section{References}

1. Jackuliak P, Payer J (2014) Osteoporosis, fractures, and diabetes. Int J Endocrinol :2-10

2. Liao CC, Lin CS, Shih CC, Yeh CC, Chang YC, Lee YW, Chen TL (2014) Increased risk of fracture and postfracture adverse events in patients with diabetes: two nationwide population-based retrospective cohort studies. Diabetes Care 37(8):2246-2252

3. Giangregorio LM, Leslie WD, Lix LM, Johansson H, Oden A, McCloskey E, Kanis JA (2012) FRAX underestimates fracture risk in patients with diabetes. J Bone Miner Res 27(2):301-308

4. Vestergaard P (2007) Discrepancies in bone mineral density and fracture risk in patients with type 1 and type 2 diabetes - a metaanalysis. Osteoporos Int 18(4):427-444
5. Mastrandrea LD, Wactawski-Wende J, Donahue RP, Hovey KM, Clark A, Quattrin T (2008) Young women with type 1 diabetes have lower bone mineral density that persists over time. Diabetes Care 31:1729-1735

6. Strotmeyer ES, Cauley JA, Orchard TJ, Steenkiste AR, Dorman JS (2006) Middle-aged premenopausal women with type 1 diabetes have lower bone mineral density and calcaneal quantitative ultrasound than nondiabetic women. Diabetes Care 29:306-311

7. Farr JN, Drake MT, Amin S, Melton LJ 3rd, McCready LK, Khosla S (2014) In vivo assessment of bone quality in postmenopausal women with type 2 diabetes. J Bone Miner Res 29(4):787-795

8. de Vittinghoff E, Sellmeyer SAV, Feingold KR, de Rekeneire N et al (2008) Diabetes-related complications, glycemic control, and falls in older adults. Diabetes Care 31(5):391-396

9. Armas LAG, Akhter MP, Drincic A, Recker RR (2012) Trabecular bone histomorphometry in humans with type 1 diabetes mellitus. Bone 50(1):91-96

10. Armas L, Recker R (2014) Type 1 diabetes mellitus effects on bone: results of histomorphometric analysis. J Bone Miner Res 29(Suppl 1). Available at http://www.asbmr.org/education/AbstractDetail? aid $=$ a4229f70-aec2-4bd0-8ee1-ad191420b13a. Accessed 2 June 2015

11. Klein, Frost, Sedlin (1964) A pilot study of lamellar bone physiology in diabetes mellitus. Henri Ford Hosp Med Bull 12:55-62

12. Leite Duarte ME, da Silva RD (1996) Histomorphometric analysis of the bone tissue in patients with non-insulin-dependent diabetes. Rev Hosp Clin Fac Med Sao Paulo 51(1):7-11

13. Krakauer JC, McKenna MJ, Buderer NF, Rao DS, Whitehouse FW, Parfitt AM (1995) Bone loss and bone turnover in diabetes. Diabetes 44(7):775-782

14. Manavalan JS, Cremers S, Dempster DW, Zhou H, Dworakowski E, Kode A, Kousteni S, Rubin MR (2012) Circulating osteogenic precursor cells in type 2 diabetes mellitus. J Clin Endocrinol Metab 97(9):3240-3250

15. Yamamoto M, Yamaguchi T, Nawata K, Yamauchi M, Sugimoto T (2012) Decreased PTH levels accompanied by low bone formation are associated with vertebral fractures in postmenopausal women with type 2 diabetes. J Clin Endocrinol Metab 97(4):1277-1284

16. Garcia-Martin A, Rozas-Moreno P, Reyes-García R, MoralesSantana S, García-Fontana B, García-Salcedo JA, Muñoz-Torres M (2012) Circulating levels of sclerostin are increased in patients with type 2 diabetes mellitus. J Clin Endocrinol Metab 97:234-241

17. Gennari L, Merlotti D, Valenti R, Ceccarelli E, Ruvio M, Pietrini MG, Capodarca C, Franci MB, Campagna MS, Calabrò A, Cataldo D, Stolakis K, Dotta F, Nuti R (2012) Circulating sclerostin levels and bone turnover in type 1 and type 2 diabetes. J Clin Endocrinol Metab 97:1737-1744

18. Gaudio A, Privitera F, Battaglia K, Torrisi V, Sidoti MH, Pulvirenti I, Canzonieri E, Tringali G, Fiore CE (2012) Sclerostin levels associated with inhibition of the $\mathrm{Wnt} / \beta$-catenin signaling and reduced bone turnover in type 2 diabetes mellitus. J Clin Endocrinol Metab 97(10):3744-3750

19. Ardawi MS, Akhbar DH, Alshaikh A, Ahmed MM, Qari MH, Rouzi AA, Ali AY, Abdulrafee AA, Saeda MY (2013) Increased serum sclerostin and decreased serum IGF-1 are associated with vertebral fractures among postmenopausal women with type-2 diabetes. Bone 56:355-362

20. Schwartz AV, Garnero P, Hillier TA, Sellmeyer DE, Strotmeyer ES, Feingold KR, Resnick HE, Tylavsky FA, Black DM, Cummings SR, Harris TB, Bauer DC (2009) Pentosidine and increased fracture risk in older adults with type 2 diabetes. J Clin Endocrinol Metab 94(7):2380-2386

21. Saito M, Kida Y, Kato S, Marumo K (2014) Diabetes, collagen, and bone quality. Curr Osteoporos Rep 12:181-188 